This is the final peer-reviewed accepted manuscript of:

J. Pacio, K. Litfin, A. Batta, M. Viellieber, A. Class, H. Doolaard, F. Roelofs, S. Manservisi, F. Menghini, M. Böttcher, Heat transfer to liquid metals in a hexagonal rod bundle with grid spacers: Experimental and simulation results, Nuclear Engineering and Design, Volume 290, 2015, Pages 27-39, ISSN 0029-5493

The final published version is available online at:

https://doi.org/10.1016/j.nucengdes.2014.11.001

Rights / License:

The terms and conditions for the reuse of this version of the manuscript are specified in the publishing policy. For all terms of use and more information see the publisher's website.

This item was downloaded from IRIS Università di Bologna (https://cris.unibo.it/)

When citing, please refer to the published version. 


\title{
Heat transfer to liquid metals in a hexagonal rod bundle with grid spacers: experimental and simulation results
}

\author{
Pacio, J. ${ }^{*}[\mathrm{a}]$ K. K. Litfin ${ }^{[a]} ;$ A. Batta ${ }^{[a]} ;$ M. Viellieber ${ }^{[a]} ;$ A. Class $^{[a]} ;$ H. Doolaard ${ }^{[b]} ;$ F. \\ Roelofs $^{[b]} ;$ S. Manservisi ${ }^{[c]} ;$ F. Menghini ${ }^{[c]} ;$ M. Böttcher ${ }^{[d]}$
}

[a] Karlsruhe Institute of Technology , Institute for Nuclear and Energy Technologies. Hermann-von-Helmholtz Platz 1, 76344, Eggenstein-Leopoldshafen, Germany

[b] NRG, Westerduinweg 3, 1755 ZG, Petten, Netherlands

[c] DIN, Laboratory of Montecuccolino, University of Bologna, Via dei Colli 16,40136, Bologna, Italy

[d] Karlsruhe Institute of Technology, Institute for Neutron and Reactor Physics. Hermann-von-Helmholtz Platz 1, 76344, Eggenstein-Leopoldshafen, Germany

*Corresponding author: Telephone: +49 72160826902. E-mail: Julio.pacio@kit.edu

Keywords: liquid metal, heat transfer, CFD, experiment

\section{Abstract}

Thermal-hydraulic is a key scientific subject to be investigated for the development of innovative reactor systems. For applications using liquid metals as coolants this task is particularly challenging due to their very low Prandtl number, preventing the application of common analogies between the turbulent transport of momentum and heat. Thus specific models and validation data with low-Pr fluids are required for representing safety-related thermal-hydraulic scenarios, such as heat transfer in fuel assemblies.

Aiming to achieve a better understanding of these flow scenarios, in the European FP7 cooperation project THINS (2010-2014) this subject is investigated at three complementary levels. An experimental campaign consisting of an electrically-heated 19-pin hexagonal rod bundle cooled by lead-bismuth eutectic LBE at typical reactor conditions in terms of operating temperature, power density and velocity. Both pre- and post-test analyses using existing numerical tools are performed for evaluating the differential pressure and heat transfer characteristics of the test section. Moreover, advanced turbulence models and numerical techniques are developed and applied to this geometry.

Overall, the goals of this project are achieved. The experiments show good degree of repeatability and provide reliable validation data. For intermediate flow rates a good agreement is observed with the results of the heat transfer simulations, based on a constant turbulent Prandtl number. Two advanced approaches for representing the turbulent heat transport considering look-up tables and a four-equation model are successfully tested, overcome the limitations of using a constant turbulent Prandtl number. Using a coarse-grid CFD approach the turbulent momentum transport along two bundles is studied, yielding a good accuracy with a 1000-fold mesh reduction. 


\section{Nomenclature}

\begin{tabular}{|c|c|}
\hline Symbol & Meaning \\
\hline \multicolumn{2}{|c|}{ Abbreviations and acronyms } \\
\hline $\mathrm{APF}$ & Anisotropic porosity formulation \\
\hline CGCFD & Coarse-grid CFD \\
\hline DNS & Direct numerical simulation \\
\hline DPA & Distributed parameter analysis \\
\hline HPLWR & High Performance Light Water Reactor \\
\hline IKET & Institute for Nuclear and Energy Technology \\
\hline INR & Institute for Neutron and Reactor Technology \\
\hline KALLA & Karlsruhe Liquid Metal Laboratory \\
\hline KIT & Karlsruhe Institute of Technology \\
\hline LBE & Lead-bismuth eutectic \\
\hline LM & Liquid metal \\
\hline LPA & Lumped parameter analysis \\
\hline NRG & Nuclear Research \& Consultancy Group \\
\hline RANS & Reynolds averaged Navier-Stokes equations \\
\hline SED & Simple eddy diffusivity \\
\hline TC & Thermocouple \\
\hline $\mathrm{TH}$ & Thermal-Hydraulic \\
\hline THINS & Thermal-Hydraulic of Innovative Nuclear Systems \\
\hline UniBo & University of Bologna \\
\hline \multicolumn{2}{|c|}{ Greek letters } \\
\hline$\varepsilon$ & Fraction of the cross sectional area covered by the spacers [-] \\
\hline$\Delta \mathrm{P}$ & Differential pressure $[\mathrm{Pa}]$ \\
\hline$\Theta$ & Dimensionless temperature [-] \\
\hline \multicolumn{2}{|c|}{ Roman letters } \\
\hline $\mathrm{d}_{\mathrm{h}}$ & Hydraulic diameter $[\mathrm{m}]$ \\
\hline $\mathrm{D}$ & Rod diameter $[\mathrm{m}]$ \\
\hline $\mathrm{F}$ & Distributed friction loss coefficient [-] \\
\hline K & Lumped pressure loss coefficient [-] \\
\hline $\mathrm{L}$ & Heated length $[\mathrm{m}]$ \\
\hline $\mathrm{Nu}$ & Nusselt number \\
\hline $\mathrm{P}$ & Pitch $=$ distance between rod centers $[\mathrm{m}]$ \\
\hline $\mathrm{Pe}$ & Péclet number \\
\hline $\operatorname{Pr}$ & Prandtl number \\
\hline Q & Thermal power $[\mathrm{W}]$ \\
\hline $\mathrm{q}_{\mathrm{w}}$ & Wall heat flux density $\left[\mathrm{W} \mathrm{m}^{-2}\right]$ \\
\hline $\operatorname{Re}$ & Reynolds number \\
\hline $\mathrm{T}$ & Temperature $[\mathrm{K}]$ \\
\hline $\mathrm{u}_{\mathrm{b}}$ & Mean bulk velocity $\left[\mathrm{m} \mathrm{s}^{-1}\right]$ \\
\hline \multicolumn{2}{|c|}{ Sub-indices and Super-indices } \\
\hline $\mathrm{B}$ & Refers to the bulk conditions \\
\hline Bdl & Refers to the rod bundle \\
\hline Sch & Refers to the internal sub-channels \\
\hline $\mathrm{Sp}$ & Refers to the grid spacers \\
\hline $\mathrm{T}$ & Turbulent \\
\hline $\mathrm{W}$ & Refers to the heated wall \\
\hline
\end{tabular}




\section{Introduction}

Liquid metals (LMs) are prominent coolants for innovative nuclear systems. Compared to water-based system, they allow high-temperature operation, lower pressures, and designing a core based on a fast-neutron spectrum and with a higher power density. These features make LMs attractive fluids for next-generation systems with a strong focus on inherent safety.

For the development of such innovative systems, thermal-hydraulics is a key scientific subject to be further investigated. In particular, available predicting models and simulation tools need to be validated against experimental data. This task is challenging due to the particular physical properties of LMs, represented by a very low Prandtl number $(\operatorname{Pr}<<1)$. Consequently the molecular diffusion of heat is much larger than that of momentum and accordingly the thermal viscous boundary layer is thicker than the hydrodynamic one. In practice, this means that common analogies (such as the Reynolds analogy) for relating the turbulent momentum and heat are not applicable. Specific models and validation data with low-Pr fluids are required for representing the heat transfer in safety-related scenarios, such as in the fuel assemblies in the core of the reactor.

The European cooperation FP7 project THINS (Thermal-Hydraulic of Innovative Nuclear Systems) was launched in 2010, aiming to achieve a better understanding of challenging thermal-hydraulic (TH) scenarios in innovative reactor systems. This project covers several topics: advanced reactor core $\mathrm{TH}$; single-phase turbulence and mixed convection, multi-phase flow and code coupling (Cheng, et al., 2010). The structure of this article, devoted to the study of heavy liquid metal cooled fuel assemblies, is as follows.

- Section 2 describes an experimental campaign performed at the Karlsruhe Liquid Metal Laboratory (KALLA) of KIT. It consist of a heated bundle of 19 pins with three grid spacers, cooled by lead-bismuth eutectic (LBE) at reactor-like operating conditions of temperature, heat flux density and flow velocities. This campaign is complemented by preliminary un-heated tests with a similar geometry in water.

- Section 3 covers pre- and post-test numerical activities, performed by two research groups, supporting the experiments.

- At the Institute for Nuclear and Energy Technology (IKET) at KIT, unstructured meshes are employed. Local mesh refinement in the spacer regions is applied to achieve good results at relatively low computational cost.

- Activities at the Nuclear Research and Consultancy Group (NRG) assess the heat transfer within the fuel bundle considering a constant turbulent Prandtl number $\left(\mathrm{Pr}_{\mathrm{t}}\right)$

- Section 4 present new model developments applicable to this type of flows.

- At the Institute for Neutron and Reactor Technology (INR) at KIT, highly resolved structured meshes are employed. Look-up tables based on DNS data for turbulent Prandtl numbers are implemented.

- At the University of Bologna (UniBo) different heat transfer models are studied. A simple eddy diffusivity (SED) model using a constant $\operatorname{Pr}_{t}$ is compared to a four equation heat turbulence model $\mathrm{k}-\varepsilon-\mathrm{k}_{\theta}-\varepsilon_{\theta}$

- At KIT-IKET the Coarse Grid CFD, an alternative to sub-channel codes is developed and applied to both fuel bundles with grid spacers and wire-wraps.

- Concluding remarks including a comparison of the results are outlined in section 5. 


\section{Experimental investigation}

The THINS project includes an experimental investigation of heat transfer in LBE, providing validation data to the numerical models described in sections 3 and 4 . A comprehensive description of this campaign has been reported in (Pacio, et al., 2014). In this work the main results and characteristics of the setup are presented. Moreover, the hydraulic analysis of this geometry is supported by preliminary un-heated experiments in water. Further details of the campaign in water can be found in (Litfin, et al., 2010).

\subsection{Description of the setup}

For this investigation the forced-convective LBE loop THEADES at KIT-KALLA was used. This facility is equipped with an active oxygen control system (Lefhalm, et al., 2001) and has wide operating ranges in terms of temperature $\left(200-450^{\circ} \mathrm{C}\right.$ ), flow rate (up to $47 \mathrm{~m}^{3} / \mathrm{h}$ ), pressure head (up to $5.9 \mathrm{bar}$ ) and installed heating and cooling capacity (up to $500 \mathrm{~kW}$ ). In a vertical test port of this loop, with upward flow, the test section sketched in Figure 1 was installed. A filter was installed upstream, preventing particles to entering the test section.

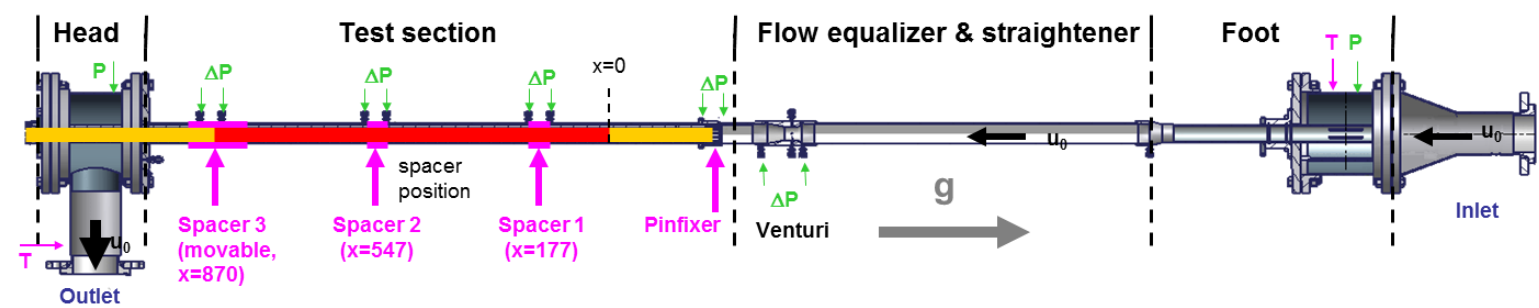

Figure 1. Side view of the test section. The LBE flow upwards (from right to left).

Downstream of a flow-straightening section a Venturi nozzle is installed for complementing the Vortex flow meter of the loop, particularly at low velocities. In a hexagonal channel a 19-rod bundle is placed, attached to the bottom to a pin-fixer. The rods have an initial un-heated length of $400 \mathrm{~mm}$, along which the velocity profile develops. In the heated region $(870 \mathrm{~mm})$ three grid spacers are placed as indicated in Figure 1. The positions of the first two spacers are fixed, while the third can be moved relative to its reference position $(-90$ to $+15 \mathrm{~mm})$. The parameters of this geometry and the operating ranges are listed in Table 1.

\begin{tabular}{|c|c|c|c|}
\hline Geometrical parameter & Value & Operating range & Value \\
\hline Rod diameter (D) & $8.2 \mathrm{~mm}$ & Temperature $(\mathrm{T})$ & $200-450{ }^{\circ} \mathrm{C}$ \\
\hline Pitch-to-diameter ratio (P/D) & 1.40 & Heat flux (Q) & $50-440 \mathrm{~kW}$ \\
\hline Number of rods / spacers & $19 / 3$ & Heat flux density $\left(\mathrm{q}_{\mathrm{w}}\right)$ & $118-1033 \mathrm{~kW} / \mathrm{m}^{2}$ \\
\hline Heated length of the rods (L) & $870 \mathrm{~mm}$ & Mass flow rate & $4.3-31.7 \mathrm{~kg} / \mathrm{s}$ \\
\hline Length of the spacers $\left(\mathrm{L}_{\mathrm{sp}}\right)$ & $25 \mathrm{~mm}$ & Prandtl number $(\operatorname{Pr})$ & $0.0147-0.0345$ \\
\hline $\begin{array}{l}\text { Hydraulic diameter of a central } \\
\text { sub-channel }\left(d_{h, s c h}\right)\end{array}$ & $9.52 \mathrm{~mm}$ & Reynolds number & $10200-128000$ \\
\hline $\begin{array}{l}\text { Hydraulic diameter of the bare- } \\
\text { bundle flow channel }\left(\mathrm{d}_{\mathrm{h}, \mathrm{bdl}}\right)\end{array}$ & $7.70 \mathrm{~mm}$ & Péclet number & $291-3600$ \\
\hline
\end{tabular}

Table 1. Geometrical parameters and operational ranges of the test section

The grid spacers are fabricated using selective laser melting and have a honeycomb structure as shown in Figure 2 (left). The ratio of the projected area of the spacers and the 
undisturbed free-flow cross-sectional area, is $\varepsilon=0.29$. A total of 38 thermocouples (TCs, 0.25 $\mathrm{mm}$ in diameter) are installed through $0.5 \mathrm{~mm}$ holes in the spacer walls, at a distance of 2.5 $\mathrm{mm}$ upstream of the spacers in the positions shown in Figure 2 (right).
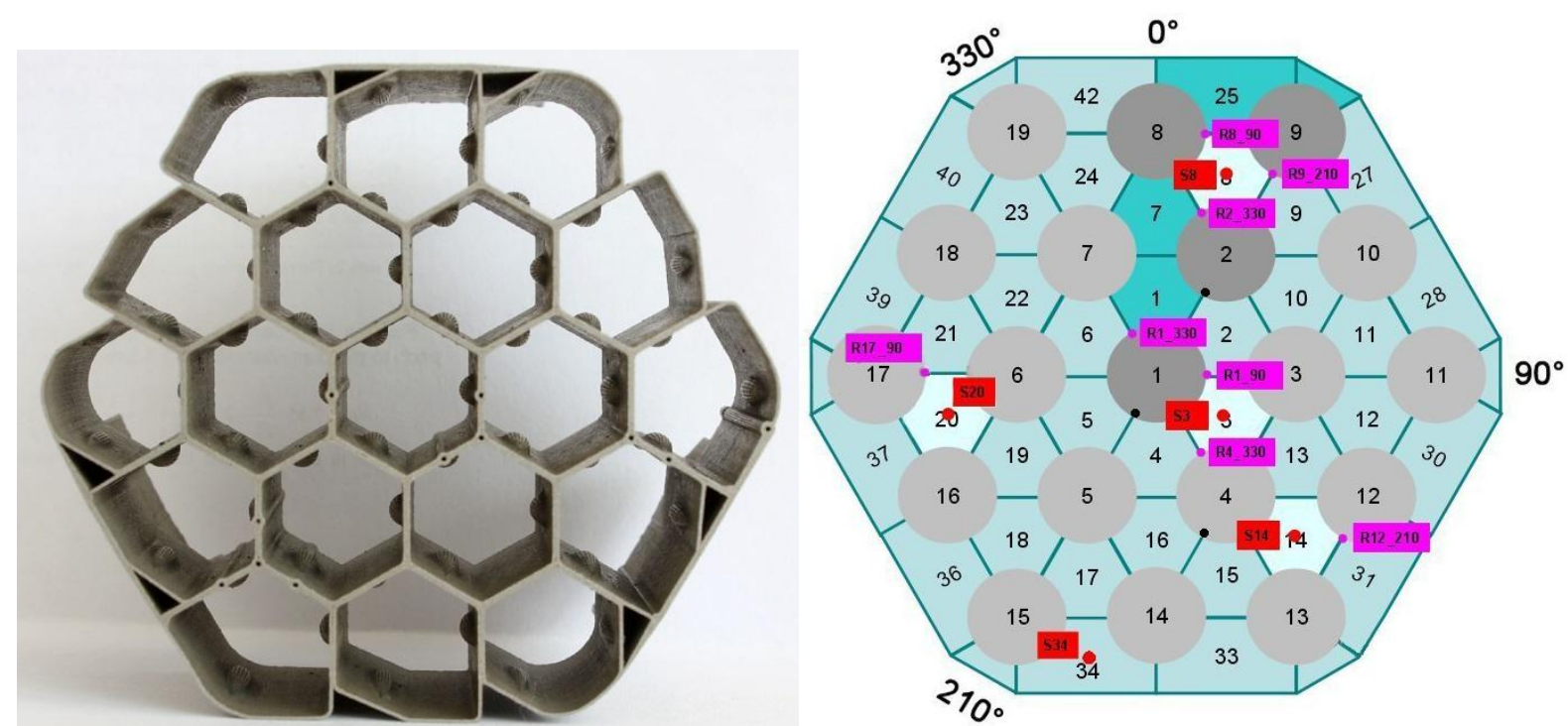

Figure 2. Details of grid spacers (top views). Left: photo. Right: schematic representation of thermocouples locations. Red $=$ sub-channel center, Pink $=$ wall temperature from outside. Black $=$ wall temperature inside cladding (only at third axial position)

The pressure drop across each spacer is measured with probes located at $-50 \mathrm{~mm}$ and +50 $\mathrm{mm}$ from their centerlines. A temperature-dependent correction is implemented so that the hydrostatic contribution (approx. 100 mbar) is excluded from the measurements. Moreover, the distributed losses can be estimated based on the total pressure difference.

\subsection{Analysis of the results}

Two contributions to the pressure drop, namely the lumped pressure drop at the spacers (left) and the distributed friction losses in the bare regions of the bundle (right), are presented in Figure 3. These are represented in terms of two non-dimensional parameters: $\mathrm{K}_{\mathrm{sp}}$ and $f$, defined in Eqs. (1) and (2), respectively.

$$
\begin{gathered}
K_{s p}=\frac{\Delta P_{s p}}{0.5 \rho u_{b}^{2}}, \\
f=\frac{\Delta P_{f}}{0.5 \rho u_{b}^{2}} \frac{d_{h, b d l}}{L} .
\end{gathered}
$$

Here, $\Delta \mathrm{P}_{\mathrm{sp}}$ is computed by subtracting the hydrostatic and acceleration terms, a distributed friction term $\Delta \mathrm{P}_{\mathrm{f}}$ is obtained by subtracting all other contributions from the total pressure drop, and $\mathrm{u}_{\mathrm{b}}$ is the mean bulk velocity.

In Figure 3 (left) the experimental values of $\mathrm{K}_{\mathrm{sp}}$ are compared to predictions. These use the model by (Epiney, et al., 2010) and (Cheng \& Todreas, 1986) for the grid spacers, and distributed friction shortly upstream and downstream, within both pressure probes, respectively. Good agreement is observed, for data included between dashed lines. Experimental points seem to tend toward a larger value of $\mathrm{K}_{\mathrm{sp}}$ for $\mathrm{Re} \rightarrow \infty$, presumably as a consequence of wall roughness (estimated around $30 \mu \mathrm{m}$ ). Moreover, the experimental points indicate good repeatability within the uncertainties and all three spacers give similar results.

In Figure 3 (right), good agreement is observed with the predictions from the correlation from (Cheng \& Todreas, 1986). Despite the large apparent uncertainties of the experimental 
data (a result of obtaining $\Delta \mathrm{P}_{\mathrm{f}}$ indirectly from other measurements) the points follow a clear

2 trend, very close to the solid line and in almost all cases within both dashed lines $( \pm 10 \%$

3 deviations).
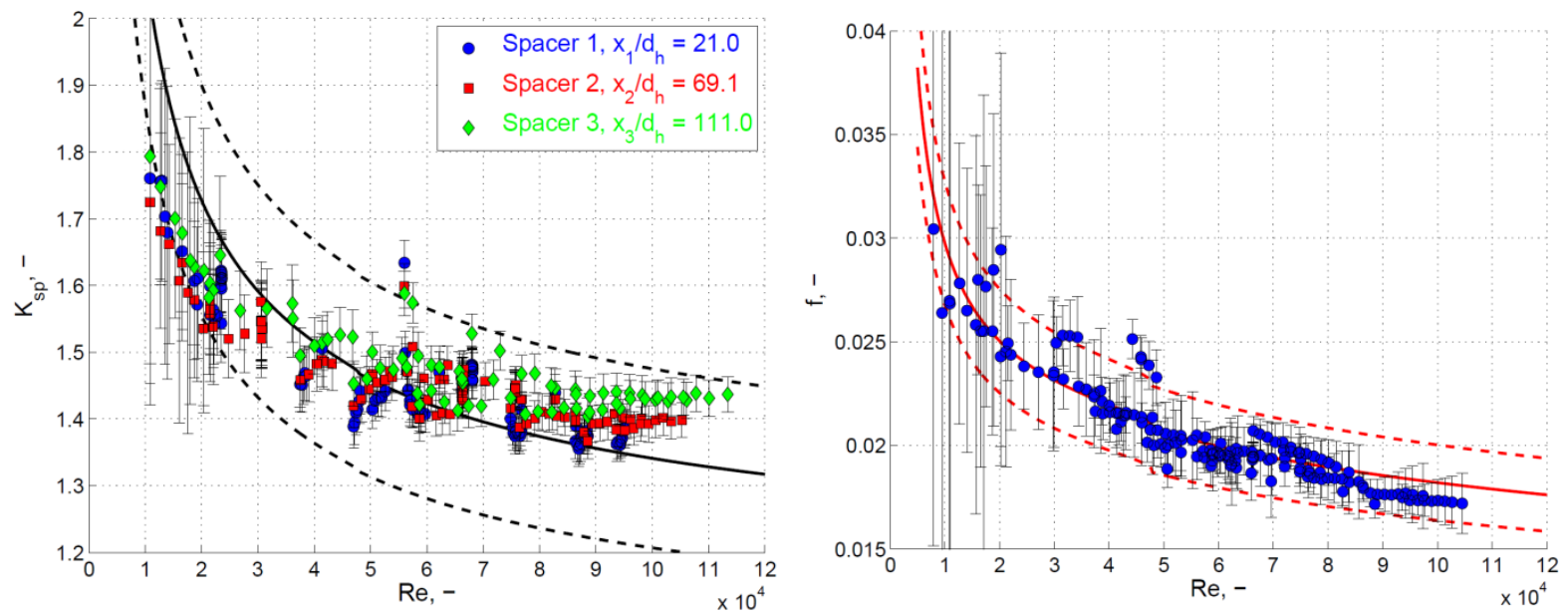

Figure 3. Pressure drop experimental results. Left: pressure loss coefficient at the spacers. Right: average friction coefficient over the bare bundle region. The solid lines indicate the prediction of the correlations and the dashed lines deviations of $\pm 10 \%$

The detailed temperature measurements are interpreted in this work in terms of the mean heat transfer coefficient $(\alpha)$, which is the relevant parameter for comparing to correlations and simulations. In non-dimensional terms, it is represented by the Nusselt number $(\mathrm{Nu})$

$$
N u=\alpha \frac{d_{h, s c h}}{\lambda}=\frac{q_{w}}{\left\langle T_{w}\right\rangle-T_{b}} \frac{d_{h, s c h}}{\lambda},
$$

where $\left\langle\mathrm{T}_{\mathrm{w}}\right\rangle$ is mean wall temperature (obtained as an average from multiple TCs) and $\mathrm{T}_{\mathrm{b}}$ is bulk temperature at that axial position (derived from an energy balance). The flow rate is represented by the Péclet number $(\mathrm{Pe})$,

$$
P e=\operatorname{Re} \operatorname{Pr}=\frac{\rho u_{b} d_{h, s c h}}{\mu} \frac{c_{p} \mu}{\lambda}=\frac{\rho c_{p} u_{b} d_{h, s c h}}{\lambda} .
$$

Figure 4 (left) shows experimental heat transfer results at the three axial positions. Good degree of reproducibility of the experiments can be inferred from the fact that the three clouds of points follow well-defined curves without major deviations from the general trend. Moreover, it is observed that at a given $\mathrm{Pe}, \mathrm{Nu}$ is $30-40 \%$ larger at the first position, compared to the other two, which are similar to each other. This is interpreted as a consequence of thermally-developing flow at the first position and fully-developed conditions further downstream. This is confirmed by moving the third spacer around its reference position. The results shown in Figure 4 (right) indicate that at a given flow rate, $\mathrm{Nu}$ is independent of axial position, within the indicated experimental uncertainties.

The fully-developed results (positions 2 and 3) are under-predicted (approx. 20\%) by the correlation of (Ushakov, et al., 1978), indicated as a solid line in Figure 4 (left). It should be noted that the experimental data are compared to an independent empirical correlation, developed over three decades ago. Moreover, the observed enhanced heat transfer could be related to a local flow acceleration upstream of the grid spacers, see e.g. (Jäger \& Sánchez, 2013). 

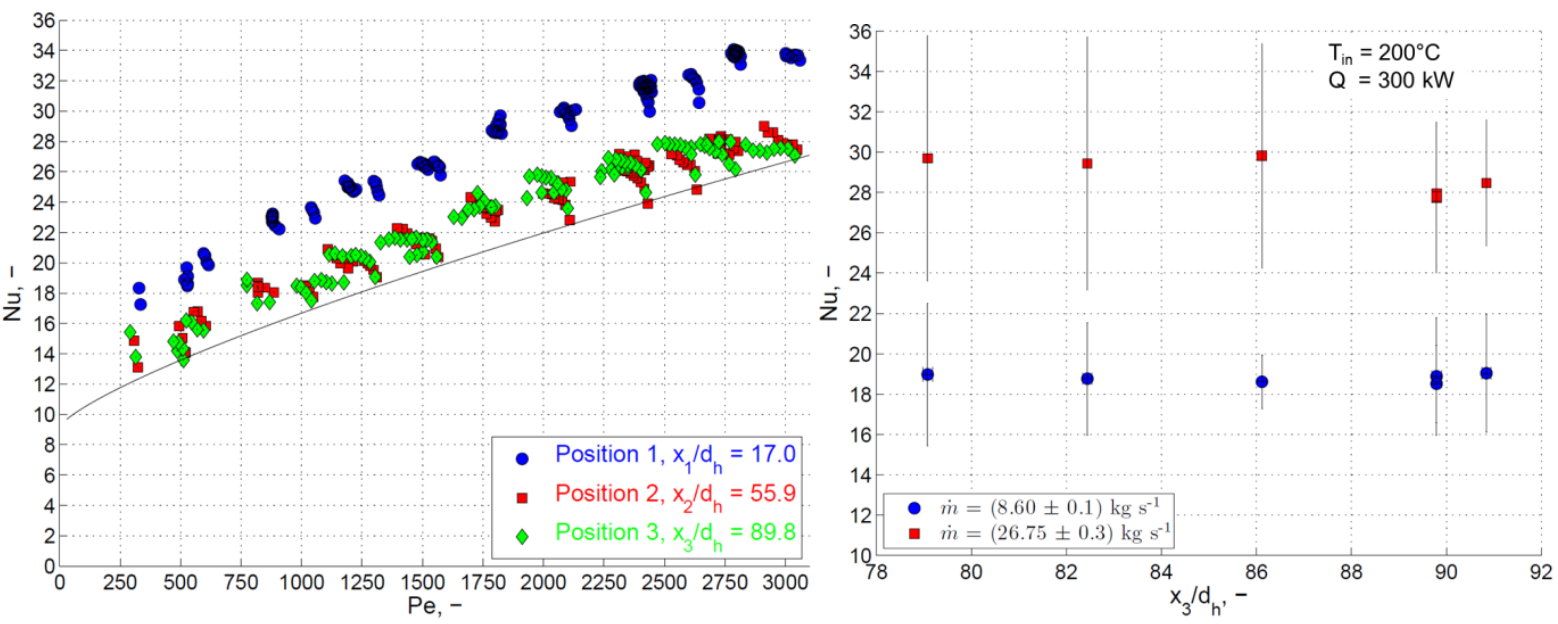

Figure 4. Experimental heat transfer results. Left: Nusselt vs. Péclet numbers at each axial position. Right: Evolution of Nusselt number with axial location around third measuring level for two selected mass flow rates and otherwise equal operating conditions.

\section{3. Numerical support}

$6 \quad$ Within this work both pre-test and post-test analyses are considered.

\subsection{Pre-test analysis}

Hydraulic studies are performed at KIT-IKET for the KALLA 19-pin rod bundle experiment (section 2). Comprehensive results of these numerical studies can be found in (Batta \& Class, 2014).

Pre-test studies support the design of the experimental test section including the flow straightener. A uniform velocity up stream of the bundle is insured by suitable design as verified in preliminary water experiments within EUROTRANS (Litfin, 2010). The commercial CFD code Star-CCM+ is used for the numerical study. In (Batta, et al., 2010) different flow domains and meshes are assessed for a flow obstruction by the spacer grid $\varepsilon=0.27$. The study shows that differential pressure across the first and second spacer grid are similar. Moreover, the friction in the inlet section and the section downstream of the spacers is almost identical, so that developing flow can be ignored. Accordingly, it is concluded that it suffixes to analyze a single spacer grid with cyclic boundary conditions. The mesh refinement study in (Batta, et al., 2010) shows that the mesh in the spacer region must be refined substantially in order to achieve mesh independent solutions. Previous studies are conducted by considering smooth surface wall conditions.

Another preliminary study investigating the LBE experiment is conducted in (Batta \& Class, 2011) prior to the construction of the experiment considering a higher blockage ratio of $\varepsilon=0.34$ compared to the water tests. Based on the previous experience in (Batta, et al., 2010) in (Batta \& Class, 2011) the computational domain is restricted to the entrance region and a single grid spacer. Two computational domains are used. The first includes all details of the geometry (including Venturi nozzle and pin fixer), see Figure 1. The second domain only covers a $60^{\circ}$ sector and is geometrically simplified. The standard $\mathrm{k}-\varepsilon$ model with high $\mathrm{y}^{+}$wall treatment is used. Unsteady computations are performed leading to a steady state solution for the tested mass flow rate of $26 \mathrm{~kg} / \mathrm{s}$. The study of different domains with uniform inflow indicates that the smallest computational domain which exploits all possible symmetries delivers comparable results to the full domain. The comparison of the differential pressure obtained from the two domains indicates a very weak effect of the entrance region. This is in contradiction to preliminary tests (Litfin, 2010) eventually leading to installation of a filter 
upstream of the test section. Moreover the sensitivity study conducted in (Batta \& Class, 2011) shows that the mesh effect is more pronounced compared to effects of wall treatment and turbulence modelling. This indicates that complex effects such as flow recirculation which require specialized turbulence models are not very pronounced in the considered bundle geometry.

\subsection{Post-test grid spacer momentum test analysis}

The tested spacer, see Figure 5 (left) and section 2, in the experiment has a slightly different dimension compared to pre-test studies, i.e., variable wall thickness, leading to $\varepsilon=0.16$ at spacer inlet, $\varepsilon=0.27$ at spacer middle and $\varepsilon=0.29$ at spacer exit. In the previous studies spacers with constant wall thickness were used. Due manufacturing by selective laser melting, the spacer has a roughness of about 35-40 $\mu \mathrm{m}$. Based on the results of previews studies (Batta, et al., 2010) (Batta \& Class, 2011), a flow domain with one spacer and a $120^{\circ}$ sector are considered, see Figure 5 (right).
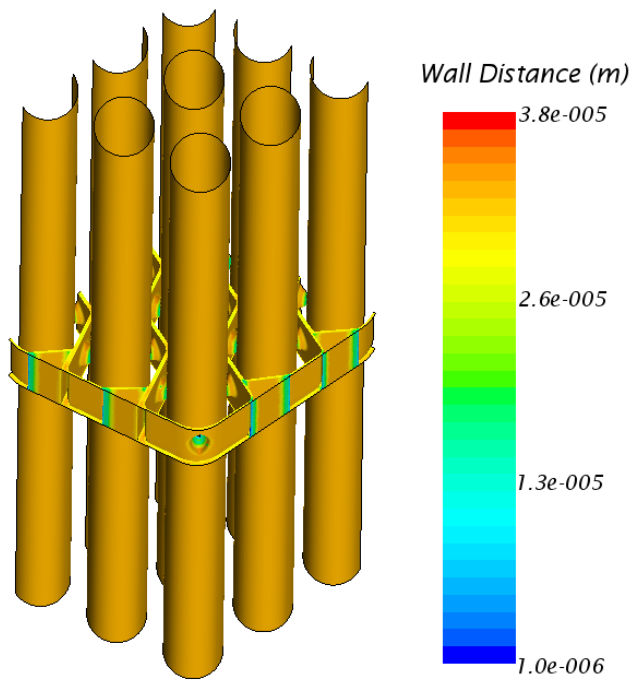

Figure 5. Left: Design of used spacer $(\mathrm{P} / \mathrm{D}=1.4 \mathrm{D}=8.2 \mathrm{~mm}$, small holes are installed with TCs. Right: contours of the $\mathrm{y}^{+}$wall distance

The simulations employ the Star-CCM+ code, high-Reynolds-number k- $\varepsilon$-turbulence model with automatic wall treatment. In the experiment the heated rods are considered smooth while the real spacer exhibits substantial surface roughness. Since the CFD code uses the minimum of $\mathrm{y}^{+}$and desired wall roughness, $\mathrm{y}^{+}$values are selected in the range of the roughness. Figure 5 (right) shows the wall distance of the cell centroid adjacent to the wall. The study is carried out for nominal mass flow rate of $26 \mathrm{~kg} / \mathrm{s}$ with uniform inlet velocity and constant fluid temperature, $\mathrm{T}=300 \mathrm{C}^{\circ}$. This corresponds to volumetric flow rate of $9.1 \mathrm{~m}^{3} / \mathrm{h}$, also considered in previous studies (Batta \& Class, 2011).

Figure 6 shows the pressure profile along selected lines crossing the spacer. In the experiment the distance between the upper and lower pressure probes is $100 \mathrm{~mm}$. Figure 6 shows that the differential pressure across this distance is approx. $25.0 \mathrm{kpa}$, while the experimentally measured value for this nominal case is $28 \mathrm{kpa}$ (Pacio, et al., 2013). The comparison yields $11 \%$ under prediction verifying the selected model settings. 


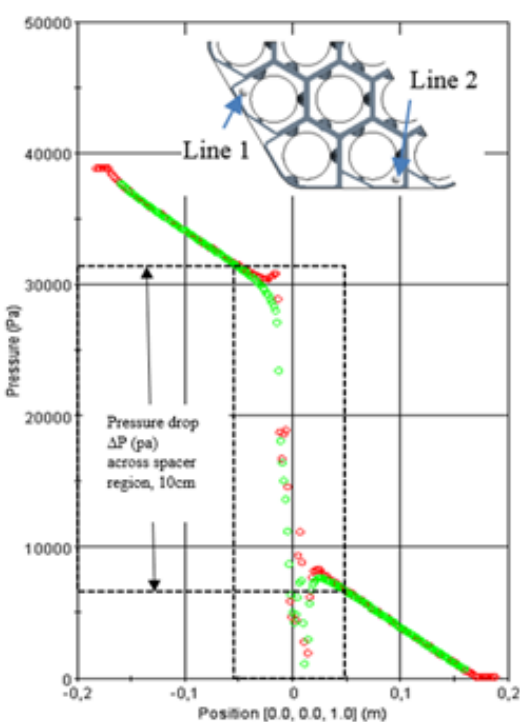

Figure 6. Pressure profile along selected lines across the spacer and differential pressure at measurement planes.

\subsection{Post-test heat transfer analysis}

Based on the experience gained during the pretest analysis a numerical grid is generated covering the complete experimental test section at NRG, also using Star-CCM+ 8.2.

\section{Model description}

The region of interest is the test section indicated in Figure 1, including the three spacers. The spacers are rotational symmetric over $120^{\circ}$, so only $1 / 3^{\text {rd }}$ of the cross-sectional area is modelled to reduce computational effort, using symmetry boundary conditions. A schematic overview of the modelled geometry and the discretization of the domain in the spacer region
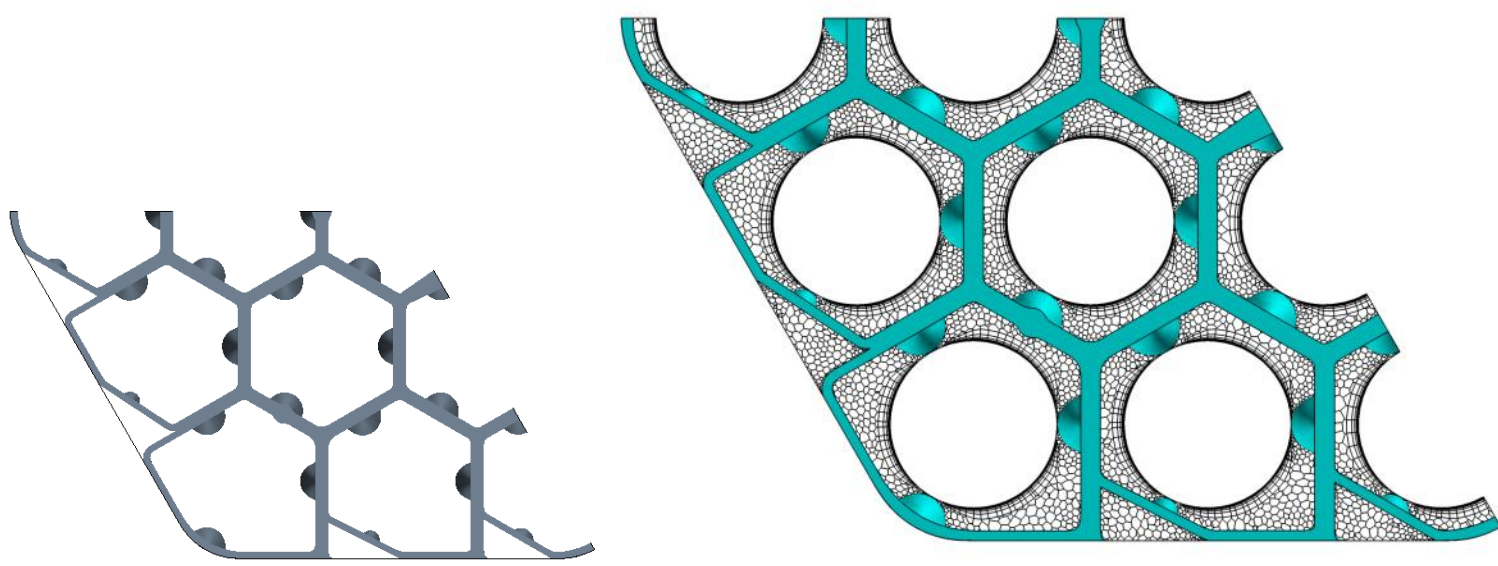

Figure 7. Schematic overview of the grid spacer and the mesh applied in the spacer region

The mesh consists of 9.9 million cells in total. The $\mathrm{y}^{+}$value in the main part of the spacerfree rod region is smaller than 0.8 for the case with the largest Reynolds number (case (2) in Table 3), and the average $\mathrm{y}^{+}$equals 0.6 in that region. The average $\mathrm{y}^{+}$values in the spacer-free region bare rod bundle region for all cases are provided in Table 3 . An overview of the most important modelling choices is provided in Table 2. The constant turbulent Prandtl number of 0.9 was applied while improved modelling approaches are being developed within THINS, e.g., by NRG as described by (Shams, et al., 2014). Latter model has successfully been tested 
1 for simpler geometries. The relevance of the choice of the turbulent Prandtl number is

2 discussed below.

3 Table 2. Numerical settings for heat transfer simulations of the 19-rod bundle

\begin{tabular}{ll}
\hline Property & Modelling choice \\
Turbulence model & SST k- $\omega$ \\
LBE & Temperature dependent properties (OECD- \\
& NEA, 2007) \\
Power input & Heat flux at the rod surface (case dependent, \\
Inlet conditions & see Table 3) \\
Outlet conditions & Mass flow rate (case dependent, see Table 3) \\
& 0 Pressure \\
Wrapper, rods and spacer & Smooth walls
\end{tabular}

\section{Simulation results}

$5 \quad$ Four experiments are selected to simulate, with Reynolds numbers in the range of $14 \cdot 10^{3}$

6 to $95 \cdot 10^{3}$ and heat input from $50 \mathrm{~kW}$ to $300 \mathrm{~kW}$ (Table 3).

7 Table 3. Cases selected to model with Star-CCM+. The last column indicates the average $\mathrm{y}^{+}$

8 in the main part of the spacer-free rod bundle region.

\begin{tabular}{llllll}
\hline Case & $\mathbf{T}_{\text {in }}(\mathbf{K})$ & $\mathbf{Q}(\mathbf{k W})$ & $\begin{array}{l}\text { Volume flow } \\
\left(\mathbf{m}^{\mathbf{3}} \mathbf{h}\right)\end{array}$ & $\mathbf{R e}_{\text {in }}\left(\mathbf{1 0}^{\mathbf{3}}\right)$ & $\mathbf{y}^{+}(-)$ \\
$\mathbf{( 1 )}$ & 473.15 & 50 & 7.87 & 56.5 & 0.4 \\
$(\mathbf{2})$ & 573.3 & 102 & 10.0 & 95.0 & 0.6 \\
$\mathbf{( 3 )}$ & 573.15 & 300 & 5.91 & 55.3 & 0.4 \\
$\mathbf{( 4 )}$ & 473.15 & 200 & 1.96 & 14.0 & 0.2 \\
\hline
\end{tabular}

The temperature distribution at the rods for case (ii) is shown in Figure 8 where the heated length is indicated. The corner rods have a higher temperature than the other rods near the

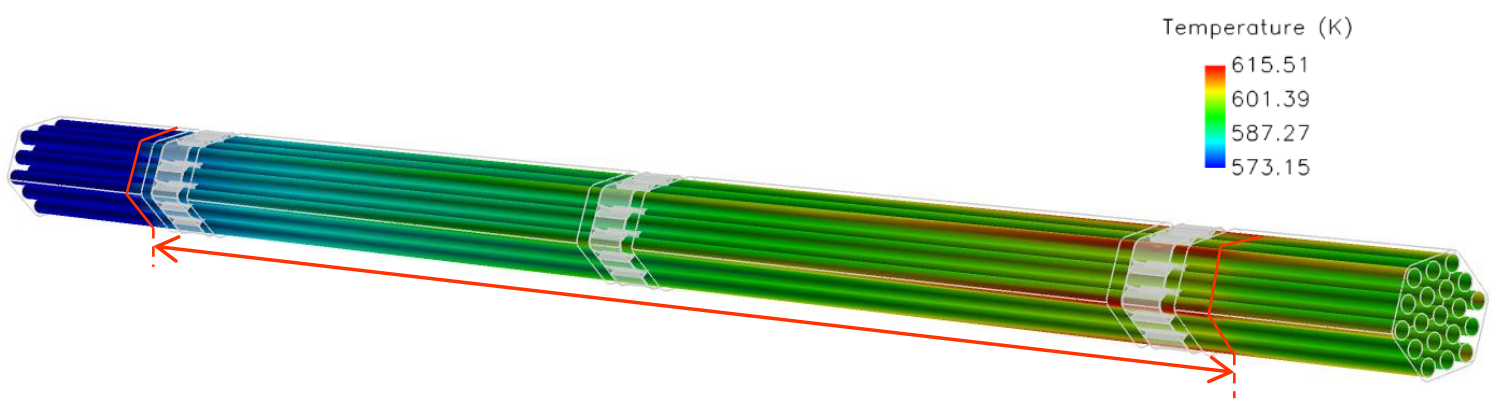

14

Figure 8. Temperature at rods for case (2). Heated length is indicated in red.

The pressure drop is selected to evaluate the hydraulics of the simulation with the experimental results. Figure 9 shows that it is well computed, i.e., approx. $\pm 25 \%$ for volume flow rates below $6 \mathrm{~m}^{3} / \mathrm{h}$. As discussed in section 3.1 this underestimation could be related to cell density and the roughness of the spacers and the rods (Batta \& Class, 2014), which is not taken into account here. 
For the comparison of the thermal flow characteristics the Nusselt number and the dimensionless maximum wall temperature $(\Theta)$, given by Eqs. (3) and (5), respectively, are evaluated. The same wall thermocouple positions as in the experiment are used to compute both thermal quantities (see Figure 2).

$$
\Theta_{w}=\frac{T_{w}-T_{b}}{q_{w}} \frac{\lambda}{d_{h, s c h}}
$$

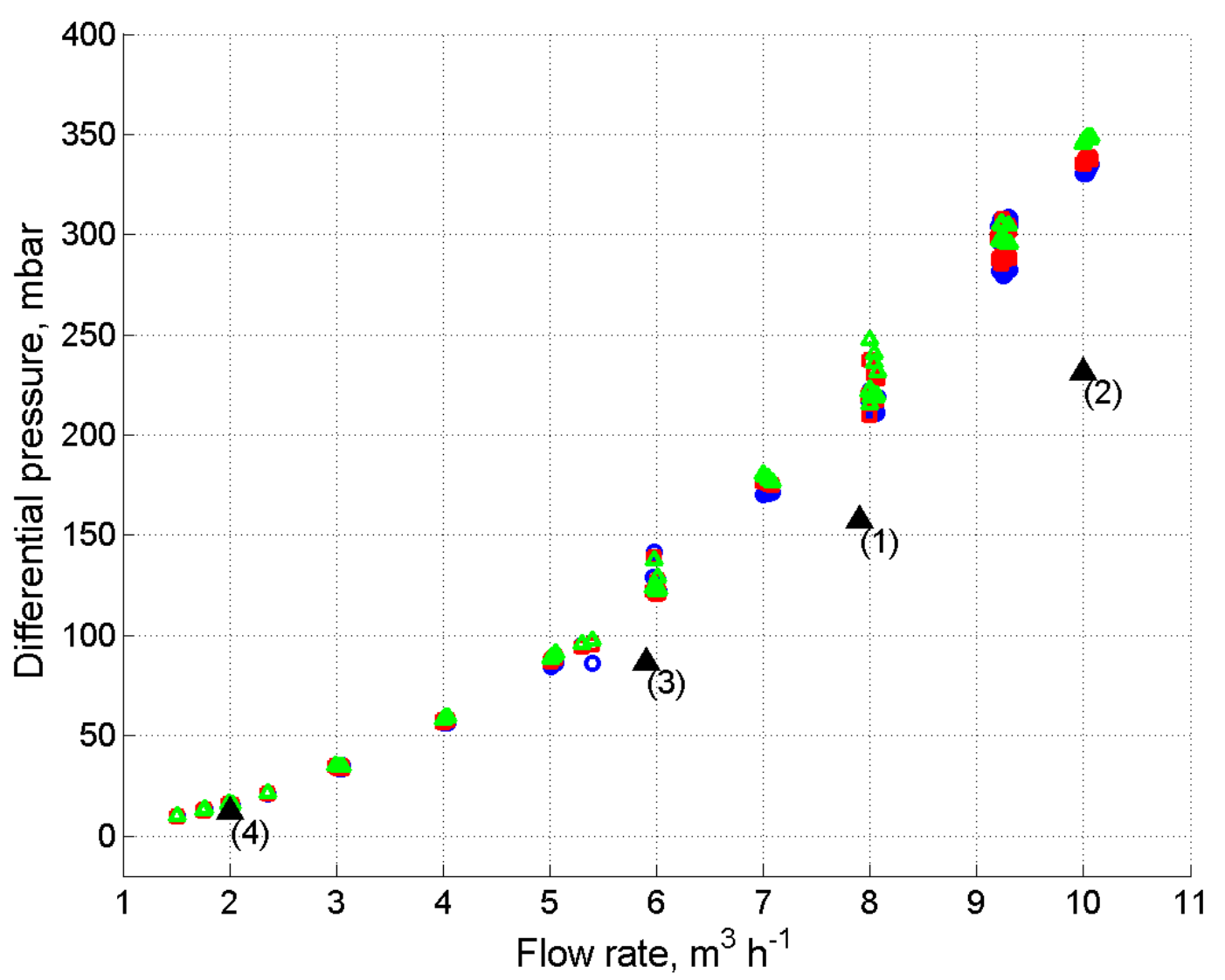

Figure 9. CFD results from Star-CCM+ compared to experimental results: Differential pressure as function of volume flow rate.

Figure 10 shows the thermal results of the simulation. The Nusselt number from cases (1) and (3) show reasonably good agreement with the first spacer of the experiments. The maximum wall temperature is predicted quite well for both cases. Since cases (1) and (3) have similar Reynolds number, it is expected that the agreement with the experiments would indeed be similar.

The case with the largest Reynolds number (2) overestimates the Nusselt number and therefore underestimates the maximum wall temperature. This is consistent with a less accurate modelling of the hydraulics of the flow in the spacer, which is observed in the pressure results in Figure 9.

Case (4) with the smallest Reynolds number underestimates the Nusselt number and therefore overestimates the maximum wall temperature. This was expected because constant $\mathrm{Pr}_{\mathrm{t}}$ heat transfer modelling exhibits limitations in the mixed and/or natural convection flow regime where molecular conduction is known to be relevant as explained by, e.g. (Grötzbach, 2013) and (Roelofs, et al., 2014). This might indicate that the modeling of the turbulent heat 
transfer is a cause of deviations. An improved heat transfer model is reported e.g. in (Shams, et al., 2014).
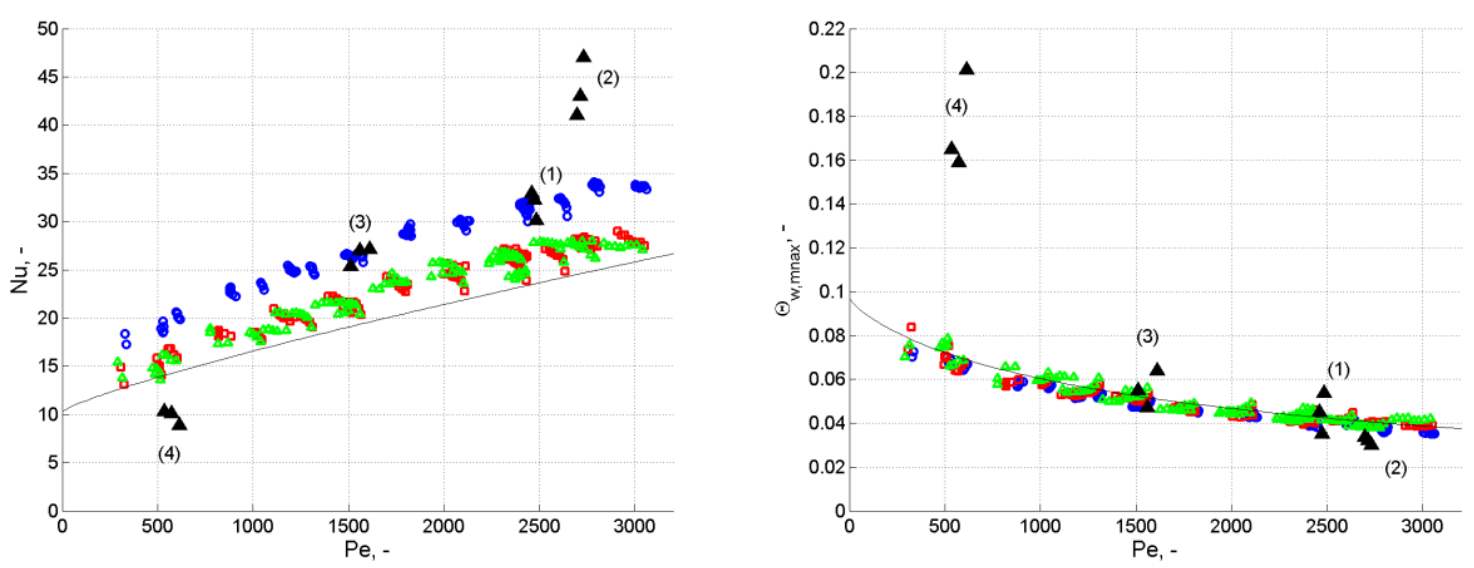

Figure 10. CFD results from Star-CCM+ compared to experimental results. Left: Nusselt number as function of Péclet number. The line indicates the correlation by (Ushakov, et al., 1978). Right: dimensionless maximum wall temperature as function of Péclet number. The line is predicted to be $1 / \mathrm{Nu}$ according to (Mikityuk, 2009).

\section{Model development}

Advanced turbulent heat transfer models for representing this type of flows are developed within the THINS project. At KIT-INR look-up tables based on DNS data for $\operatorname{Pr}_{t}$ are implemented, see section 4.1. At UniBo a four-equation model $\mathrm{k}-\varepsilon-\mathrm{k}_{\theta^{-}}-\varepsilon_{\theta}$ is compared to simple eddy diffusivity (SED) results based on a constant $\operatorname{Pr}_{t}$, see section 4.2. At KIT-IKET the Coarse Grid CFD approach is developed as an alternative to sub-channel codes, see section 4.3 .

\subsection{Look-up table approach}

In order to overcome the limitations of the constant $\mathrm{Pr}_{t}$ approximation for assessing the heat transfer in the heated rod bundle experiment, tabulated $\operatorname{Pr}_{t}$ data are implemented together with a quiet complex structured mesh.

\section{Model description}

In conventional Reynolds analogy the turbulent Prandtl number is assumed to be equal to unity, which assumes a similarity of the viscous and thermal diffusion in boundary layers. In liquid metals, molecular thermal diffusion is very high and may even dominate over turbulent diffusion which corresponds to values of $\operatorname{Pr}_{t}$ well above unity.

In contrast to models which solve additional transport equations (see e.g. section 4.2), here an approach is proposed where $\operatorname{Pr}_{t}$ is interpolated by look-up tables with local dependencies on Re, Pr, and $\mathrm{y}^{+}$. Figure 11 shows raw data generated by direct numerical simulations in simpler geometries entering the look up tables. It should be noted that the look-up table approach is currently limited to forced-convective flows. 


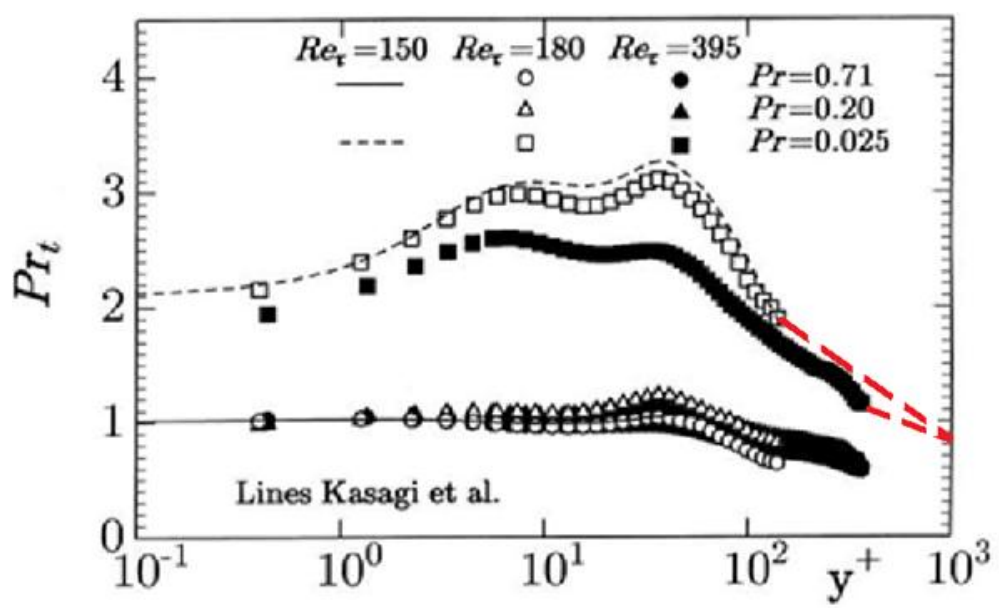

Figure 11. Turbulent Prandtl numbers for 2D channel flow from DNS. Source: (Kawamura, et al., 1999)

\section{Model application}

In order to minimize numerical diffusion in rod bundle simulations a fully structured mesh was developed using Pointwise meshing software. Also heat conduction in the rod and spacer solids is taken into account. Further details are given by (Böttcher, 2013). The CFD model represents a $120^{\circ}$ sector of the 19-pin experimental assembly and contains more than 33.4 million cells with cell spacing at the heated surfaces of $0.01 \mathrm{~mm}$. At a Reynolds number of 86000 averaged $\mathrm{y}^{+}$values of about 4 at the rod surfaces could be obtained.

Interpolation results of $\mathrm{Pr}_{\mathrm{t}}$ for various flow rates, i.e. Reynolds numbers are shown in Figure 12, indicating that the constant $\mathrm{Pr}_{\mathrm{t}}$ regime is only reached for Re beyond 77000 .
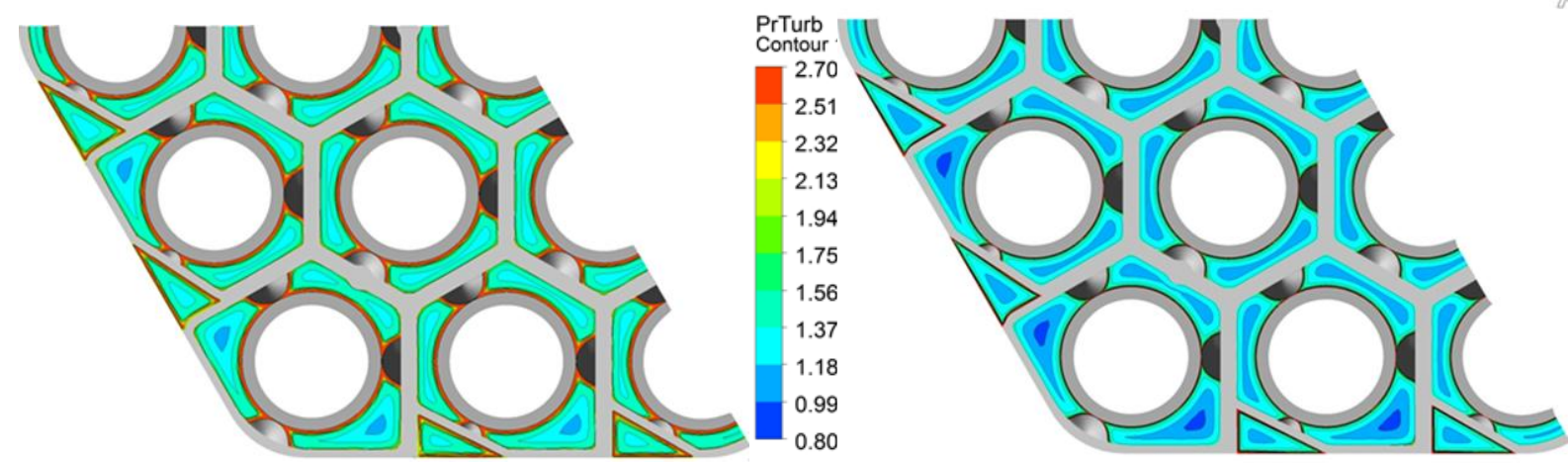

Figure 12. $\mathrm{Pr}_{\mathrm{t}}$ in central spacer position at $\mathrm{Re}=7700$ (left) and $\mathrm{Re}=77000$ (right)

Figure 13 (left) presents surface temperature scans of the central rod through the spacer touching points. The heater surface temperature first decreases as consequence of the spacer blocking effect. Further down-stream a separation zone is observed, where the heat transfer condition significantly deteriorates. Downstream of the separation zone heat transfer recovers and the rod surface cooling improves. For comparison a simulation with $\operatorname{Pr}_{t}=1.5$ (red curve) is performed. Figure 13 (right) shows corresponding Nusselt numbers with deviations of up to $20 \%$. 

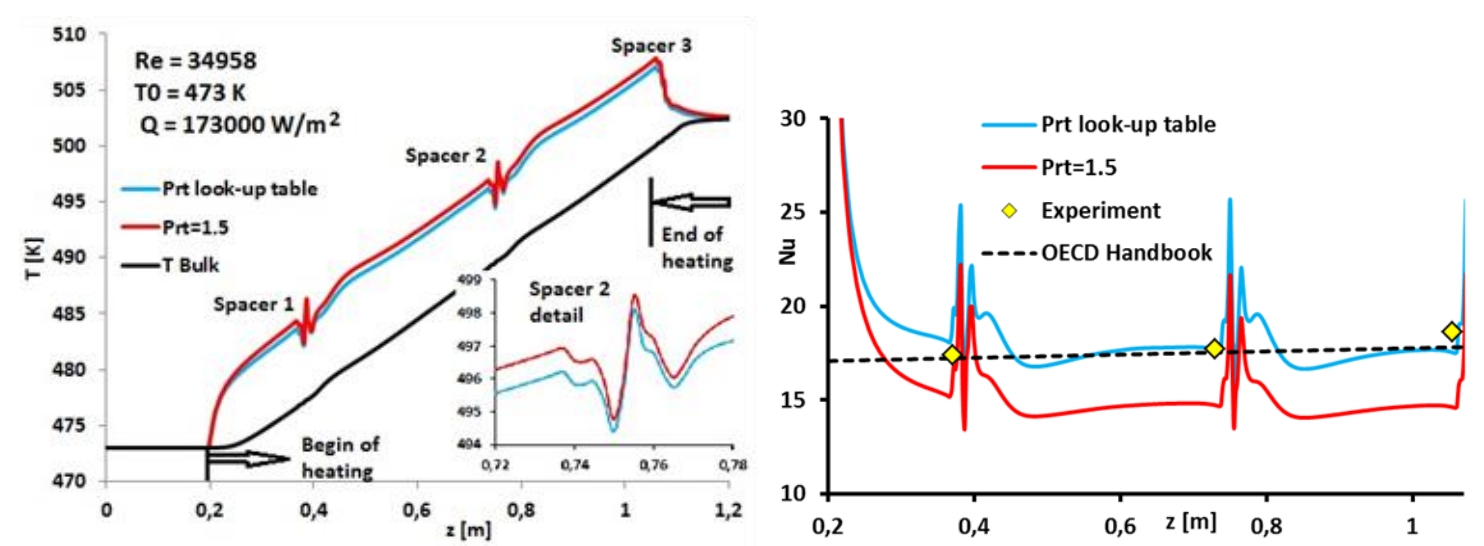

Figure 13. Axial profiles of wall temperature and Nusselt number calculated using a look-up

\subsection{Simple eddy diffusivity and four-parameter models}

The turbulent Prandtl number $P r_{t}$ used in the design of nuclear plant components with liquid metal coolant should be carefully evaluated since constant turbulent Prandtl models may be inappropriate to compute the heat turbulence flux in many geometrical configurations. Two different turbulent heat transfer models are evaluated at UniBo for this 19-pin rod bundle geometry: the simple eddy diffusivity model (SED) and the heat transfer $k-\varepsilon-k_{\theta}-\varepsilon_{\theta}$ four equation model.

In order to compute the turbulent heat flux $\overline{u^{\prime}{ }_{l} T^{\prime}}$ many approximated heat turbulence models have been developed in recent years. The SED model is implemented in all commercial codes, such as Ansys-Fluent, while the $\mathrm{k}-\varepsilon-\mathrm{k}_{\theta}-\varepsilon_{\theta}$ four-equation model is still in developing stage. In the SED model an isotropic approximation is used and the turbulent heat flux is written as in Eq. (6), where $\alpha_{\theta}$ is the turbulent thermal diffusivity.

$$
\overline{u_{i}^{\prime} T^{\prime}}=-\alpha_{\theta} \frac{\partial T}{\partial x_{i}}
$$

The simplest choice for $\alpha_{\theta}$ is $\alpha_{\theta}=C_{\theta} k \tau_{u}$ with $C_{\theta}=0.1=C_{\mu} / 0.9$ and $\tau_{u}=k / \epsilon$ in order to reproduce the following standard form

$$
\alpha_{\theta}=\frac{C_{\mu} k^{2}}{P r_{t} \epsilon}=\frac{v_{t}}{P r_{t}}
$$

In a similar way to the $\mathrm{k}-\varepsilon$ dynamical turbulence model, where $v_{t}=v_{t}(k, \varepsilon)$, one can set the turbulent thermal diffusivity to $\alpha_{\vartheta}=C_{\vartheta} k \tau$ with $\tau=\tau\left(k_{\theta}, \varepsilon_{\theta}\right)$, where $k_{\theta}$ and $\varepsilon_{\theta}$ are variables solving two appropriate transport equations. In analogy with the corresponding dynamical definitions $k_{\theta}$ is the average temperature square fluctuation and $\varepsilon_{\theta}$ is its dissipation defined as

$$
k_{\theta}=\frac{1}{2} \overline{T^{\prime 2}}, \quad \varepsilon_{\theta}=\frac{v}{\operatorname{Pr}} \overline{\left(\frac{\partial T^{\prime}}{\partial x_{j}}\right)^{2}}
$$

With these definitions the characteristic heat turbulence time $\tau_{\theta}$ is set to $k_{\theta} / \epsilon_{\theta}$ and the heat-dynamical time ratio $R$ to $\tau_{\theta} / \tau_{u}$. For details one can see (Abe, et al., 1995) (Manservisi \& Menghini, 2014) (Manservisi \& Menghini, 2014). 


\section{Simulation results}

The integral heat measurements obtained in section 2 may be used to evaluate the CFD heat turbulence model in the 19-pin rod bundle geometry. In particular an assembly with 19 fuel rods with diameter $\mathrm{D}$ and pitch $\mathrm{P}$ considered in Table 1. The hexagonal bundle geometry has an axial length of $2.5 \mathrm{~m}$, it is heated only along the last $870 \mathrm{~mm}$ and for this case a constant heat flux of $360 \mathrm{~kW} / \mathrm{m}^{2}$ is selected. The walls of the 19-pin rod bundle assembly are considered adiabatic. This geometry is very complex, due to the presence of a large number of surfaces and therefore the symmetry can be used to divide the hexagonal region into 12 parts and keep low the number of computational mesh cells. The computational simulation is limited to this minimal geometry which has four heated surfaces, bordering on the duct where the coolant flows, five surfaces of symmetry and an adiabatic wall, as shown in Figure 14.
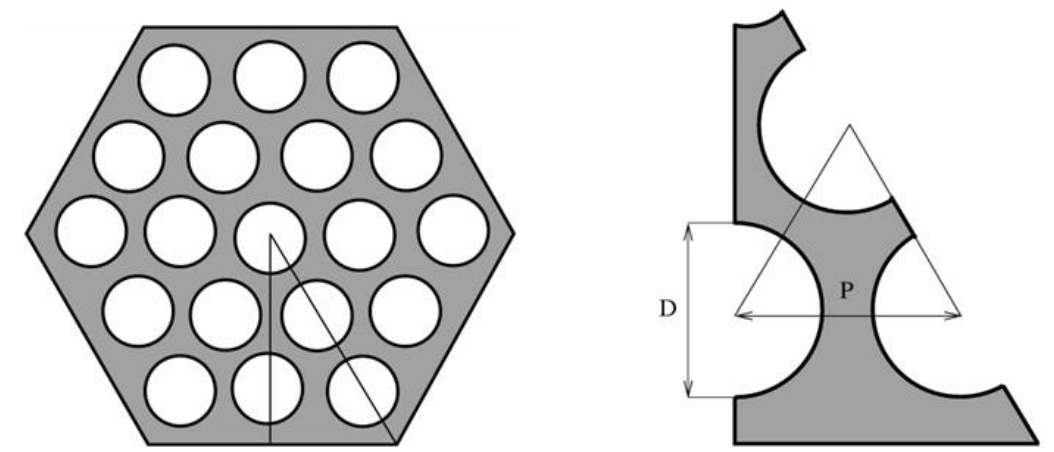

Figure 14. Simulation geometry of the 19-pin hexagonal bundle.

The CFD simulations with the SED model are performed with ANSYS-Fluent. Standard turbulent boundary conditions are imposed at the inlet and the flow is let to develop along the non-heated region (1.63 m long), beyond which a uniform heat flux is imposed. A fine discretization is needed in this region in order to obtain $y^{+}<1$ in all heated walls to use near wall approach for imposing boundary conditions. For that purpose the adaptive mesh refinement algorithm implemented in Ansys-Fluent is used, adapting the mesh mainly close to the boundary and in the fully developed region.

In order to compute the Nusselt number curve as a function of Péclet number seven cases are considered, with average velocities $\mathrm{v}=0.2,0.4,0.5,0.7,1,1.5$ and $2 \mathrm{~m} / \mathrm{s}$. These seven cases correspond approximately to Péclet numbers $\mathrm{Pe}=270,540,670,940,1330,2000$ and 2670 , respectively. The turbulence model used in the numerical simulations is the SST $\kappa-\omega$ model with transitional flow option and low Reynolds correction.

The wall temperature is an average, weighted by the temperature of the four heated walls which is computed directly from the mean surface integrals while the bulk temperature is computed by integrating the product between the temperature and the vertical velocity over the corresponding plane section.

The results obtained in term of Nusselt number are presented in Figure 15 (on the left) where a comparison between the SED model with different $\operatorname{Pr}_{t}$ and Ushakov correlation for triangular rod bundles (U1.4) is reported. On the right of Figure 15 the Nusselt number as a function of Pe number is compared with the experimental results discussed in the previous section and Ushakov correlation (U1.4). The experimental measurements have been performed at three different locations along the axial direction: $\mathrm{z}=17 / \mathrm{D}_{\mathrm{h}}(\mathrm{POS} 1), \mathrm{z}=55.9 \mathrm{D}_{\mathrm{h}}$ (POS2) and the last at $\mathrm{z}=90 \mathrm{D}_{\mathrm{h}}(\mathrm{POS} 3)$. The location POS3 has been considered to be in a fully developed region, so it is labeled (EXP).

Nusselt number as a function of Pe number is shown in Figure 16 (on the left) for the SED model and compared with the experimental results (EXP) and Ushakov correlation (U1.4). In 

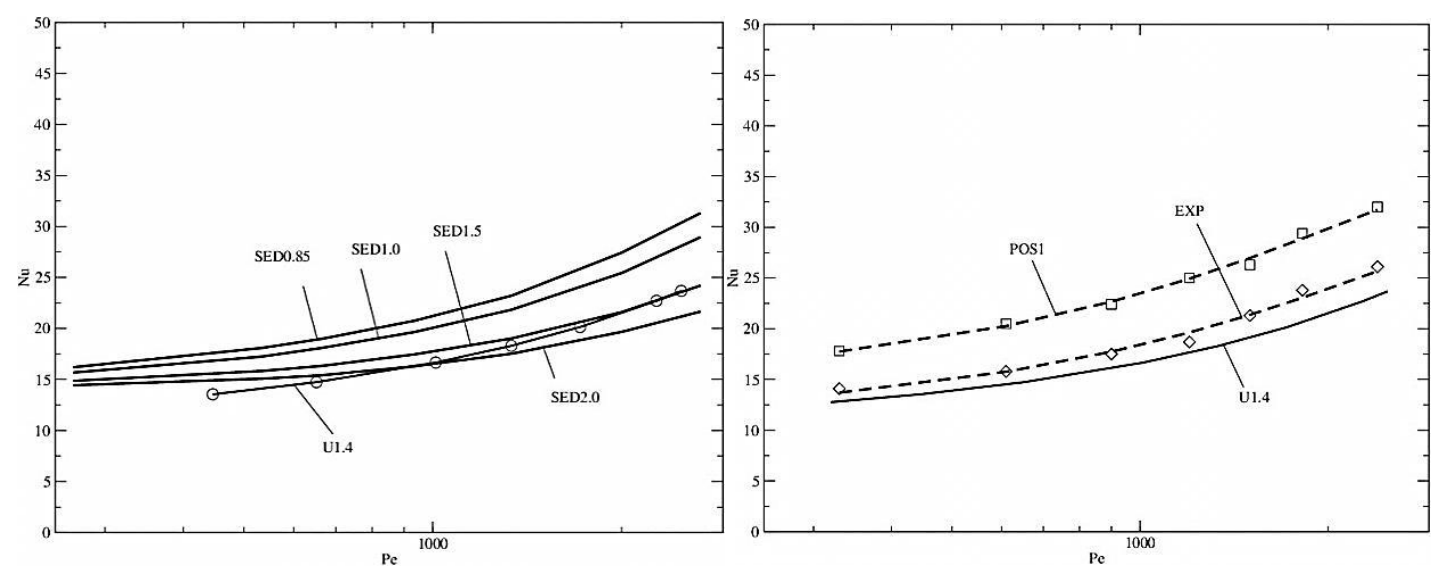

Figure 15. SED model. On the left Nusselt number $\mathrm{Nu}$ as a function of Pe number for SED model with Prt $=0.85$ (S0.85), 1.0 (S1.0), 1.5 (S1.5) and 2 (S2.0) compared with Ushakov correlation (U1.4). On the right $\mathrm{Nu}$ as a function of Pe for the experimental results (EXP) and Ushakov correlation (U1.4). The experimental results at the position $\mathrm{z}=17 \mathrm{Dh}$ are shown with label POS1.

this Figure we report only the two cases with $\mathrm{Pr}_{t}=1.5(\mathrm{~S} 1.5)$ and $2(\mathrm{~S} 2.0)$ that are close to experimental data.

The simulations with the $\mathrm{k}-\varepsilon-\mathrm{k}_{\theta}-\varepsilon_{\theta}$ four equation heat turbulence model have been performed with a finite-element in-house code. The code has been tested with DNS and experimental data as reported in (Manservisi \& Menghini, 2014) (Manservisi \& Menghini, 2014). With this model only the fully developed part of the flow has been considered. In order to compute the behavior of the heat exchange as a function of Péclet numbers we consider seven cases with average inlet velocity as in the previous case. The turbulence model used in the numerical simulations is the Abe-Nagano k- $\varepsilon$ model with second order corrections (Abe, et al., 1995). For the $\mathrm{k}_{\theta}-\varepsilon_{\theta}$ two-equation system see (Manservisi \& Menghini, 2014) (Manservisi \& Menghini, 2014). On the right of Figure 16 the Nusselt number of the $\mathrm{k}-\varepsilon-\mathrm{k}_{\theta}-\varepsilon_{\theta}$ heat transfer model is compared to the experimental results (EXP) and Ushakov correlation (U1.4). Both the SED and the $\mathrm{k}-\varepsilon-\mathrm{k}_{\theta}-\varepsilon_{\theta}$ heat transfer model can approximate the experimental integral results. The main problem of the SED model is that the $\operatorname{Pr}_{t}$ should be known "a priori" for each Péclet number. Model performance of temperature point-wise distributions should be evaluated when appropriate data are available.
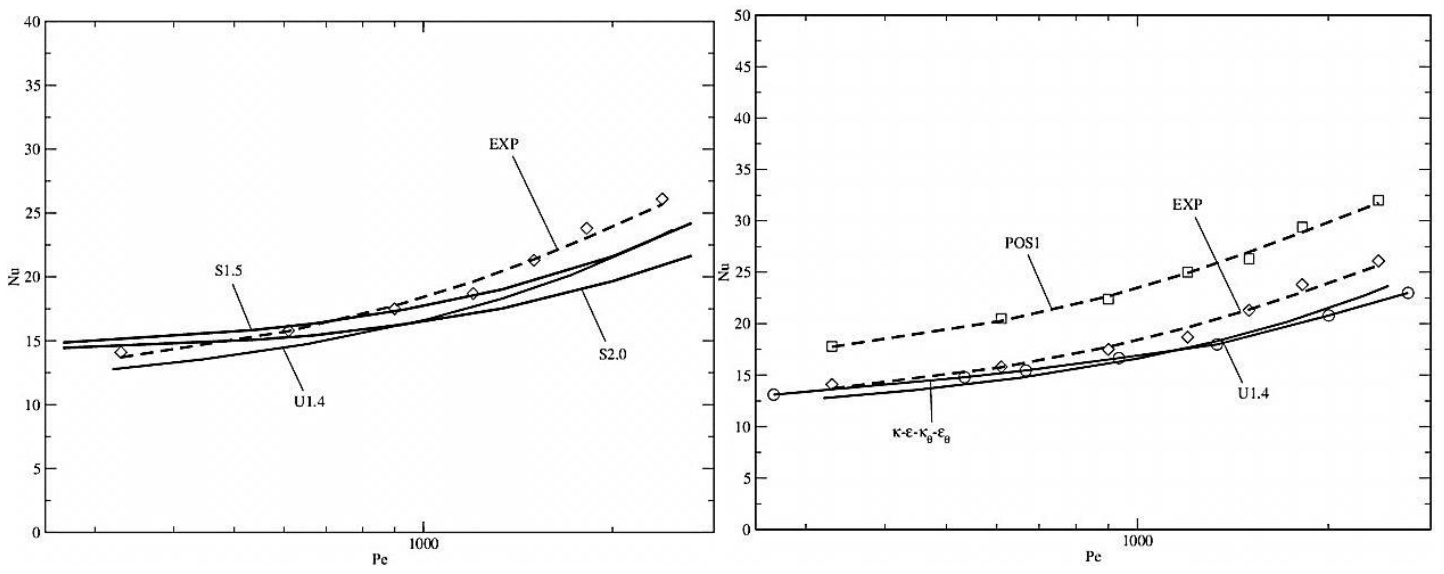

24 Figure 16. SED and $\mathrm{k}-\varepsilon-\mathrm{k}_{\theta}-\varepsilon_{\theta}$ model. On the left $\mathrm{Nu}$ number as a function of Pe number for Prt $=1.5(\mathrm{~S} 1.5)$ and $2(\mathrm{~S} 2.0)$ compared with the experimental results (EXP) and Ushakov correlation (U1.4). On the right $\mathrm{Nu}$ number with the $\mathrm{k}-\varepsilon-\mathrm{k}_{\theta}-\varepsilon_{\theta}$ heat transfer model compared with the experimental results (EXP) and Ushakov correlation (U1.4). 


\subsection{Coarse-Grid-CFD Methodology}

The core of a nuclear reactor is a few meters in height and in diameter. It is composed of several hundred fuel assemblies which are again composed of tenth of fuel rods with a diameter of about $10 \mathrm{~mm}$. Therefore the relevant length scales for CFD simulations range from the sub millimeter range, relevant for the sub channels and spacers up to several meters. Describing such a multi scale approach is challenging and the historical approach was to use integral descriptions. These methods are the lumped parameter (LPA) methods (sub-channel analyses/ 1D system analysis) which are based on integral equations and tuned by experiments, see Figure 17.

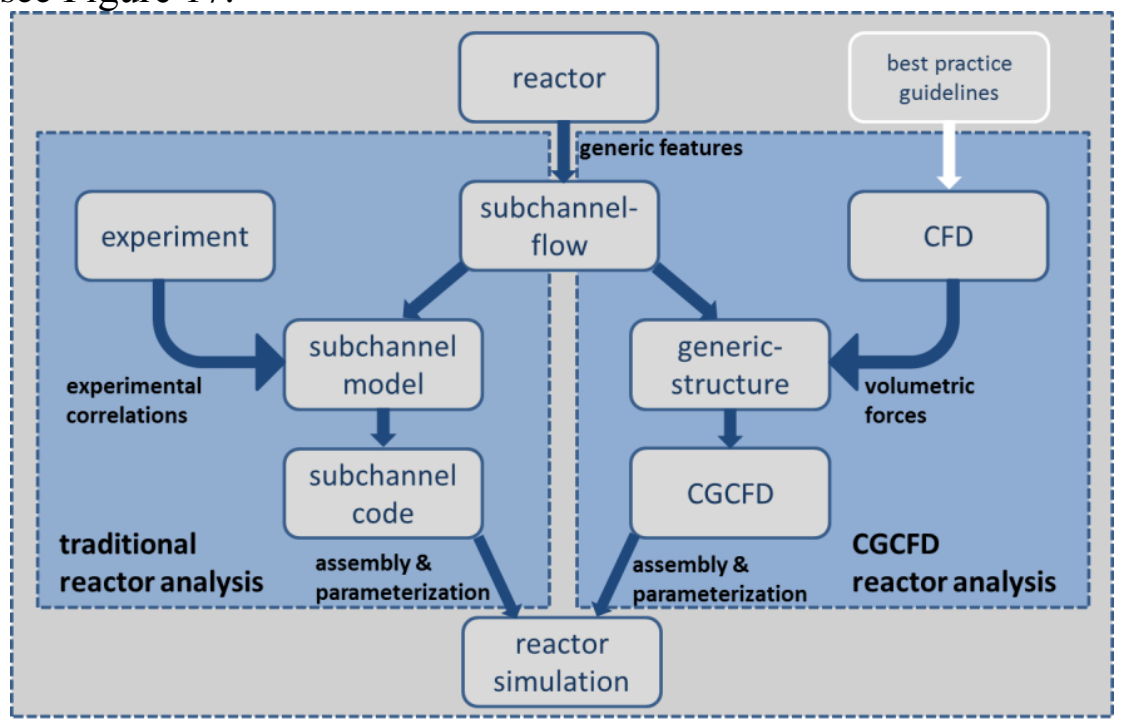

Figure 17. Sub-channel analysis and CGCFD approach. Traditional reactor analysis is based on comprehensive experimental campaigns. CGCFD tries to replace experimental investigations by use of detailed CFD simulations.

A numerical approach studied at KIT-IKET is presented aiming to reduce the need of experiments for tuning lumped-parameter models (Viellieber \& Class, 2012). In this CGCFD approach, only the used detailed CFD models and corresponding best practice-guidelines must be verified for fuel assembly thermo hydraulics, see Figure 17.

\section{Coarse-Grid-CFD development:}

The origin of the Coarse-Grid-CFD Method is the High Performance Light Water Reactor (HPLWR) project of the European Union (EU) (Himmel, 2009). The driving reason for the development of the method was the lack of experimental data applicable to the proposed reactor concept. Hence, it was not possible to resort to validated experimental correlations for the lumped parameter models. This also holds for any innovative nuclear reactor system as e.g. the THINS project. Another challenge is the lack of the computational resources needed to perform reactor wide CFD simulations with state of the art distributed parameter analyses (DPA) methods. It will persist for years to come even though high performance computers (HPC) continuously develop (compare Figure 18). On today's HPCs like the BlueGene or Tihane2 it is still not possible to perform a complete reactor core simulation, resolving all relevant length scales.

These limitations dictated the general framework of the CGCFD. The first requirement within the CGCFD methodology is to make experimental investigations used to tune subchannel analysis and 1D system codes (almost) obsolete. The second requirement was to provide a computational effective DPA method that enables simulations of the thermal hydraulics inside a complete reactor core avoiding extensive use of HPC. 


\section{The Coarse-Grid-CFD Method:}

The CGCFD method takes advantage of experience gained in the early 1970s when all

CFD simulations were under-resolved. The Coarse-Grid-CFD is based on a computational efficient Euler equation solver which obviously needs closure to account for viscous effects, i.e. non resolved physics. Closure is achieved by volumetric forces extracted from detailed DPA-CFD simulations of a part of the complete geometry under investigation. Thereby replacing the experimental or empirical input, used to tune sub-channel analysis codes by a detailed DPA-CFD simulation. The detailed DPA-CFD simulation can either be a DNS, LES, or a RANS CFD simulation (compare Figure 18). Later on the extracted volumetric forces are parameterized which is the analog of defining correlations in LPA. Parameterization omits performing detailed CFD simulation for all flow conditions. The extended Euler equations permit using coarse meshes at least 100-1000 times smaller than the meshes in the representative DPA, used to tune the CGCFD. The methodology proved to be a computational effective method thus, from the computational point of view, enabling simulation of the complete reactor core. A detailed description of the methodology can be found in (Viellieber, et al., 2013) and (Viellieber \& Class, 2012).

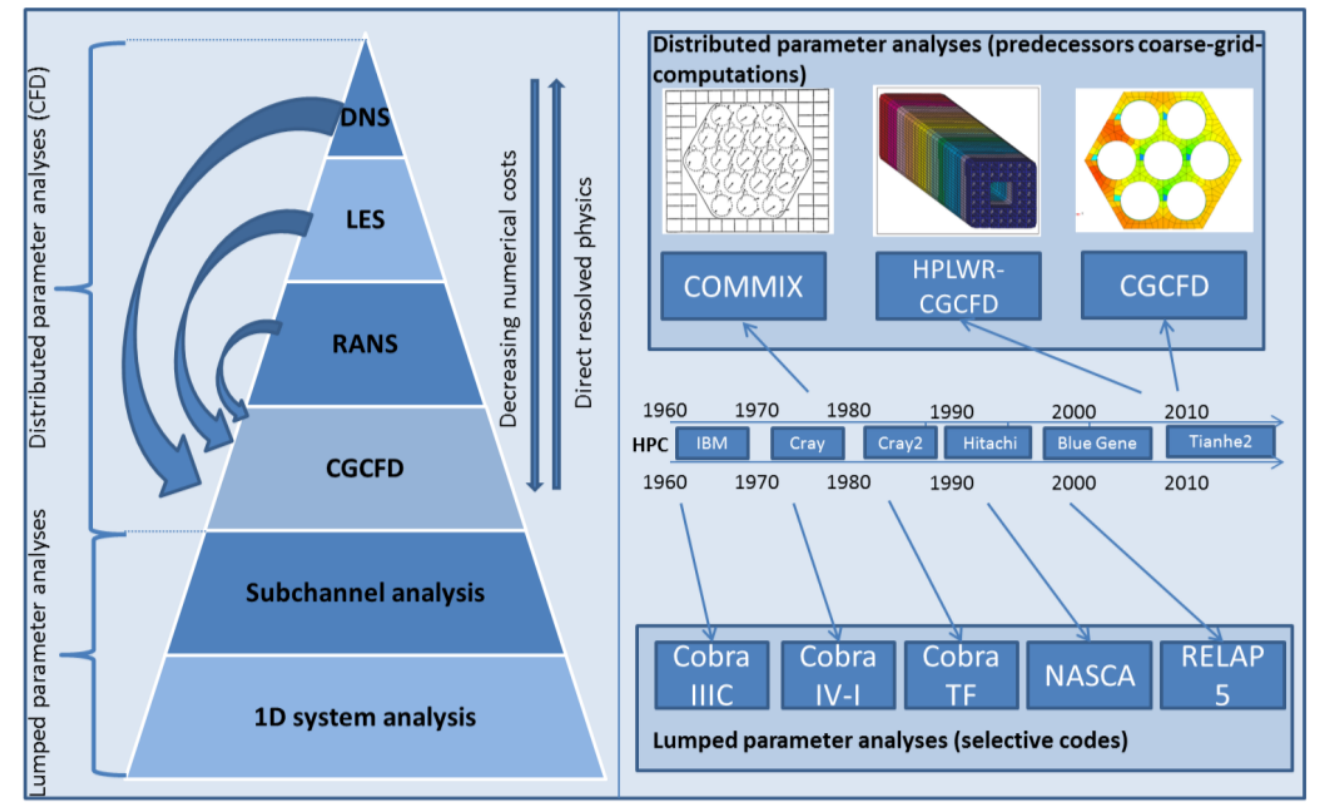

Figure 18. Classification of CGCFD within classical simulation methods for thermal hydraulic simulations highlighting DPA methods used to tune CGCFD simulations (left) and evolution of the sub-channel analysis and predecessors of CGCFD (right). CGCFD permits reactor wide simulations without extensive use of high performance computers (HPC) (Chien, et al., 1993), (Himmel, 2009).

\section{Development of the Coarse-Grid-CFD within the THINS project:}

Initially the development of the CGCFD by (Himmel, 2009) was performed using the commercial code STAR CD which was selected due to nonlinear turbulence models (not easily available elsewhere at that time). The main drawback for the development of the CGCFD within this code was its limited user interface. Within the THINS project, the method was implemented into OpenFOAM which became attractive due to the fast growing model implementations. This open source software allows implementing automated assignments between the detailed DPA meshes and the CGCFD meshes. Thus it became possible to use arbitrary meshes for the CGCFD simulations whereas the hand coding represented a major obstacle for mesh flexibility in the previous implementation. Later on the mathematical formulation of the methodology advanced leading to better results in particular for pressure 
distribution. The work-around solutions of early CFD to gain useful solutions on underresolved meshes, exempli gratia in the COMMIX code (Chien, et al., 1993) where assessed and the anisotropic porosity formulation (APF) was adopted in the CGCFD. The APF is particularly useful since it no longer requires resolving all geometrical details like spacer grids and wire wraps. Meshes intended for CGCFD feature a few cells for the resolution of a subchannel. These result in non-body conformal meshes especially in regions with spacer grids or other built in parts like pin fixers (compare Figure 19). Note similarity to immersed boundary methods and the extreme coarsening typically used in CGCFD.

During the THINS project several simulations including rod bundles with wire wrapped spacer grids where performed applying anisotropic porosity. Figure 19 (left) shows CGCFD results on a $60^{\circ}$ sector of the 19 pin fuel bundle discussed in section 3.1. The detailed simulations are analyzed and the corresponding sub-grid forces are generated. The grid spacer which is represented by several millions of cells in the DPA is now represented by less than 1000 cells. Moreover all geometrical details are ignored and cast into APF parameters. Yet the simulated pressure profile is in good agreement.

Figure 19 (right) shows results of a 7 pin wire-wrap fuel bundle which was studied within the framework of THINS. For the DPA methods the wire-wrap represents a major challenge due to the presence of line and point contacts between rods and wires and small inclination angles and the necessity to use a fine axial mesh all over the complete length. In CGCFD the wire is modelled by the APF. Due to the absence of strong pressure gradients a coarser axial mesh can be used. The pressure and the velocity profile is nice agreement with DPA results. Further information about the covered cases can be found in (Roelofs, et al., 2012) and (Viellieber, et al., 2013).
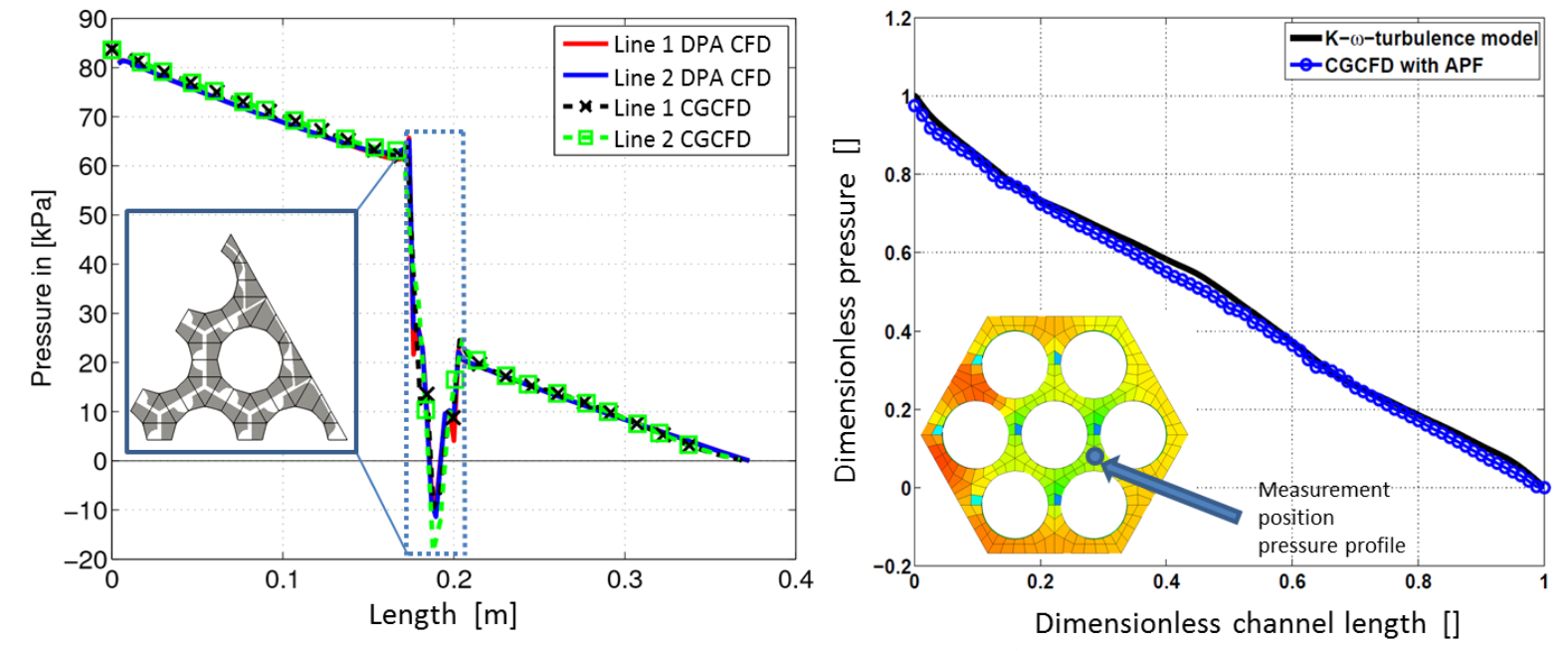

Figure 19. Pressure profile along rod bundles. Left: rod bundle with spacer grid: comparison of pressure profiles of CGCFD simulation versus representative detailed DPA simulation. Blue inset within the figure represents spacer region meshed with an APF-CGCFD mesh. Right: wire-wrapped rod bundle: pressure profile and cross-section velocity distribution. Note: wire wraps are represented by the anisotropic porosity.

\section{Conclusions}

Within the THINS project (2010-2014) a liquid-metal cooled fuel bundle is studied experimentally, numerically, and advanced models are developed. Overall the goals of this project are achieved. A good agreement is observed between experiments and simulations. 
Moreover, the turbulence models and numerical techniques developed are successfully applied to this geometry. They present promising approaches for future applications in challenging thermal-hydraulic problems in innovative energy systems.

A comprehensive experimental campaign considering a LBE-cooled 19-rod bundle with three grid spacers is conducted. Both differential pressure and heat transfer are analyzed, including detailed temperature measurements (38 TCs) in selected sub-channels and at the cladding. Similar results are observed at the second and third axial positions, demonstrating fully-developed conditions as well as repeatability of the experiments. The results are compared to empirical correlations. Good agreement is observed for the pressure losses, within 10\% deviation. The measured Nusselt numbers are approx. 20\% larger than predicted.

Pre-test and post-test analyses are provided by two research groups supporting the experiments. Best-practice guidelines for modelling this geometry are defined by parametric pre-test studies and confirmed in the post-test analysis. Heat transfer simulations using a constant turbulent Prandtl number $\left(\operatorname{Pr}_{t}\right)$ show decent agreement with the experiments for intermediate flow rates.

Two advanced models are applied to overcome the limitations of using a constant $\operatorname{Pr}_{t}$.

Firstly, look-up tables for interpolating $\operatorname{Pr}_{t}$ as a function of $\operatorname{Re}, \operatorname{Pr}$ and $\mathrm{y}^{+}$are generated based on DNS data and applied to the bundle studied in the experiments. It is observed that a constant $\mathrm{Pr}_{\mathrm{t}}$ regime is only reached for Re beyond 77000. Compared to constant $\operatorname{Pr}_{\mathrm{t}}$ results, deviations up to $20 \%$ in the Nusselt number are observed, although the wall temperature is hardly affected for forced-convection.

Secondly, a parametric study of constant values of $\operatorname{Pr}_{t}$ indicates a large effect of this parameter on the Nusselt number. Moreover, the experimental data is not well represented by a single value of $\operatorname{Pr}_{t}$ over the studied Péclet range. A four-equation $k-\varepsilon-k_{\theta}-\varepsilon_{\theta}$ model is introduced for the turbulent heat transport. This model shows good results for the considered flow rates without tuning parameters.

A coarse-grid CFD approach is developed using highly under-resolved meshes. Sub-grid data are extracted from fully-resolved simulations. In this context, few representative simulations provide the necessary data for assessing the complete reactor core. Two bundles are studied: one with 19 pins and grid spacers and a second one with 7 rods and wire-wraps. In both cases a 1000-fold mesh reduction proves sufficient to resolve the physics, in agreement with detailed calculations.

These thermal-hydraulic studies performed within the THINS project show a good agreement between experimental data and numerical simulations. Moreover, advanced models are developed for overcoming the limitations of current approaches and are successfully tested for forced convection. Ongoing and future investigations within several European projects (e.g. SEARCH, MAXSIMA) shall be focused on mixed convection and other safetyrelated phenomena, such as flow blockages.

Acknowledgements

The authors would like to acknowledge the support of the European Union in the framework of the EU 7th framework project THINS, grant number 249337.

\section{References}

Abe, K., Kondoh, T. \& Nagano, Y., 1995. A new turbulence model for predicting fluid flow and heat transfer in separating and reattaching flows-II. Thermal field calculations. 
Batta, A. \& Class, A., 2011. Study of enhanced entrance pressure losses in a rod bundle experiment employing heavy liquid metal coolant. Toronto, Proceedings of the 14th International Topical Meeting on Nuclear Reactor Thermalhydraulics, NURETH-14. Batta, A. \& Class, A., 2014. Numerical study of pressure drop in heavy-liquid metal 19-pin KALLA rod bundle experiment employing a grid spacer. Modena, Proceedings of the THINS 2014 International Workshop, January 20-22, 2014.

Batta, A., Class, A., Litfin, K. \& Wetzel, T., 2010. Numerical Study on Flow Distribution and Turbulent Flow in XT-ADS Rod Bundle Water Experiment. Shanghai, Proceedings of the NUTHOS-8, October 10-14, 2010.

Böttcher, M., 2013. CFD Investigation of LBE Rod Bundle Flow. Karlsruhe: The Connector.

Cheng, S.-K. \& Todreas, N. E., 1986. Hydrodynamic models and correlations for bare and wire-wrapped hexagonal rod bundles - Bundle friction factors, subchannel friction factors and mixing parameters. Nuclear Engineering and Design, 92(2), pp. 227-251.

Cheng, X. et al., 2010. European Activities on Cross-Cutting Thermal-Hydraulics of Innovative Nuclear Systems. Shanghai, Proceedings of the NUTHOS-8, October 10-14, 2010,.

Chien, T., Domanus, H. \& Sha, W., 1993. COMMIX-PPC: A Three-Dimensional Transient Multicomponent Computer Program for Analyzing Performance of Power Plant Condensers, : Argonne National Laboratory.

Epiney, A., Mikityuk, K. \& Chawla, R., 2010. TRACE qualification via analysis of the EIR gas-loop experiments with smooth rods. Annals of Nuclear Energy, 37(6), pp. 875-887.

Grötzbach, G., 2013. Challenges in low-Prandtl number heat transfer simulation and modelling. Nuclear Engineering and Design, Volume 264, pp. 41-55.

Himmel, S., 2009. Modeling of the flow pattern in a HPLWR fuel assembly with wire wraps, Karlsruhe: Karlsruhe Institute of Technology.

Jäger, W. \& Sánchez, V., 2013. Validation of the heat transfer enhancement models for spacer grids in the system code TRACE. Nuclear Engineering and Design, Volume 265, pp. 272287.

Kawamura, H., Abe, H. \& Matsuo, Y., 1999. DNS of turbulent heat transfer in channel flow with respect to Reynolds and Prandtl number effects. International Journal of Heat and Fluid Flow, 20(3), pp. 196-207.

Lefhalm, C., Knebel, J. \& Mack, K., 2001. Kinetics of gas phase oxygen control system (OCS) for stagnant and flowing Pb-Bi systems. Journal of Nuclear Materials, 296(1), pp. 301-304.

Litfin, K., 2010. Final report for the fuel bundle experiment at KALLA, Karlsruhe: EUROTRANS.

Litfin, K., Batta, A., Class, A. \& Wetzel, T., 2010. Flow distribution and turbulent heat transfer measurements in a hexagonal LBE rod bundle.. XI'an, Proceedings of the 18th International Conference on Nuclear Engineering ICONE18.

Manservisi, S. \& Menghini, F., 2014. A CFD four parameter heat transfer turbulence model Transfer, Volume 69, pp. 312-326.

Manservisi, S. \& Menghini, F., 2014. Triangular rod bundle simulations of a CFD k- $\epsilon-k \theta-\epsilon \theta$ heat transfer turbulence model for heavy liquid metals. Nuclear Engineering and Design, Volume 273, pp. 251-270. 
1 Mikityuk, K., 2009. Heat transfer to liquid metal: Review of data and correlations for tube 2 bundles. Nuclear Engineering and Design, 239(4), pp. 680-687.

3 OECD-NEA, 2007. Handbook on Lead-bismuth Eutectic Alloy and Lead Properties,

4 Materials Compatibility, Thermal-hydraulics and Technologies. : OECD/NEA Nuclear

5 Science Committee Working Party on Scientific Issues of the Fuel Cycle Working Group on

6 Lead-bismuth Eutectic.

7 Pacio, J. et al., 2013. Mid-term report on experimental rod bundle data, Karlsruhe: THINS.

8 Pacio, J. et al., 2014. Heavy-liquid metal heat transfer experiment in a 19-rod bundle with grid

9 spacers. Nuclear Engineering and Design, Volume 273, pp. 33-46.

10 Roelofs, F. et al., 2012. Simulating fuel assemblies with low resolution CFD approaches.

11 Nuclear Engineering and Design, pp. 548-559.

12 Roelofs, F. et al., 2014. Status and perspective of turbulence heat transfer modellign for the

13 industrial application of liquid metal flows. Modena, Proceedings of the THINS 2014

14 International Workshop, January 20-22, 2014, p. Paper number 009.

15 Shams, A. et al., 2014. Assessment and calibration of an Algebraic Heat Flux Model for low 16 Prandtl Fluids. International Journal of Heat and Mass Transfer, Volume Under review.

17 Ushakov, P., Zhukov, A. \& Matyukhin, N., 1978. Heat transfer to liquid metals in regular 18 arrays of fuel elements. High Temperature (USSR), 15(10), pp. 1027-1033.

19 Viellieber, M. \& Class, A., 2012. Anisotropic Porosity Formulation of the Coarse-Grid-CFD. 20 Annaheim, Proceedings of the 20th International Conference on Nuclear Engineering

21 ICONE20.

22 Viellieber, M., Dietrich, P. \& Class, A., 2013. Investigation of a Wire Wrapped Fuel

23 Assembly with the Anisotropic Coarse-Grid-CFD. Interrnational Journal for Nuclear Power, 24 10, pp. 573-575. 